\title{
Extent of lymphadenectomy is associated with oncological efficacy of sublobar resection for lung cancer $\leq \mathbf{2} \mathbf{~ c m}$
}

\author{
Brendon M. Stiles, MD, ${ }^{a}$ Jialin Mao, MD, ${ }^{\mathrm{b}}$ Sebron Harrison, MD, ${ }^{\mathrm{a}}$ Benjamin Lee, MD, \\ Jeffrey L. Port, MD, ${ }^{a}$ Art Sedrakyan, MD, ${ }^{b}$ and Nasser K. Altorki, MD ${ }^{a}$
}

\section{ABSTRACT}

Background: Sublobar resection (SLR) is an alternative to lobectomy for early non-small cell lung cancer. Comparative effectiveness of these 2 approaches might be modified by the extent of lymph node dissection.

Methods: We utilized the Surveillance, Epidemiology, and End Results ProgramMedicare dataset to identify patients with stage I non-small cell lung cancer aged 66 years or older with tumor size $\leq 2 \mathrm{~cm}$. We compared patient characteristics with $t$ tests for continuous variables and $\chi^{2}$ tests for categorical variables. Kaplan-Meier curves were constructed to determine overall survival (OS) and cancer-specific survival (CSS). We evaluated OS and CSS among propensitymatched cohorts undergoing lobectomy versus SLR, particularly as it related to extent of lymphadenectomy.

Results: Among 2757 lobectomies and 1229 SLR procedures performed for stage I tumors $\leq 2 \mathrm{~cm}$, we propensity-matched 1124 patients from each group. Patients undergoing SLR were more likely to have no lymph nodes sampled $(46.9 \%$ vs $6.4 \% ; P<.001$ ). OS (hazard ratio [HR], 1.48; 95\% confidence interval [CI], 1.29-1.69) and CSS (HR, 2.06; 95\% CI, 1.41-3.02) were worse following SLR. When propensity-matched cohorts of patients with at least 1 lymph node removed ( $\mathrm{n}=567$ each group) were examined, the HRs for survival for SLR decreased (OS HR, 1.38; 95\% CI, 1.12-1.69; CSS HR, 1.58; 95\% CI, 0.97-2.57). Finally, when cohorts were propensity matched for $\geq 9$ lymph nodes examined $(n=103$ each group), there was no difference in OS (HR, 0.84; 95\% CI, 0.50-1.39) or CSS (HR, 1.10; 95\% CI, 0.35-3.41).

Conclusions: SLR leads to fewer lymph node removed and is associated with inferior survival compared with lobectomy. A more extensive lymphadenectomy may be associated with equivalent survival between matched patients undergoing SLR and lobectomy. (J Thorac Cardiovasc Surg 2019;157:2454-65)

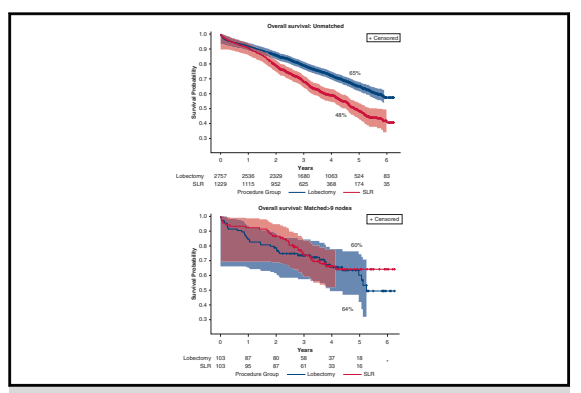

After matching, survival of sublobar resection (red) is equivalent to lobectomy (blue).

Central Message
Patients with lung cancer undergoing sublobar
resection often have inadequate lymph node ex-
amination compared with those undergoing lo-
bectomy. More thorough lymph node
examination may improve survival.

\section{Perspective}

Patients with lung cancer undergoing sublobar resection often have inadequate lymph node examination compared with those undergoing lobectomy. More thorough lymph node examination may improve survival.

See Commentaries on pages 2466 and 2468 .
The oncologic equivalency of sublobar resection (SLR) to lobectomy for clinical stage I non-small cell lung cancer (NSCLC) remains to be determined. Randomized trials from North America (Cancer and Leukemia Group B

From the ${ }^{\mathrm{a} D e p a r t m e n t s ~ o f ~ C a r d i o t h o r a c i c ~ S u r g e r y ~ a n d ~}{ }^{\mathrm{b}}$ Healthcare Policy and Research, Weill Cornell Medicine, New York-Presbyterian Hospital, New York, NY.

Read at the 98th Annual Meeting of The American Association for Thoracic Surgery, San Diego, California, April 28-May 1, 2018.

Received for publication May 1, 2018; revisions received Jan 9, 2019; accepted for publication Jan 21, 2019; available ahead of print April 4, 2019.

Address for reprints: Brendon M. Stiles, MD, Division of Thoracic Surgery, Department of Cardiothoracic Surgery, Weill Cornell Medicine of Cornell University, Ste M404, 525 E 68th St, New York, NY 10065 (E-mail: brs9035@med.cornell.edu). $0022-5223 / \$ 36.00$

Copyright @ 2019 Published by Elsevier Inc. on behalf of The American Association for Thoracic Surgery

https://doi.org/10.1016/j.jtcvs.2019.01.136
140503) and Japan (Japanese Clinical Oncology Group JCOG0802) will hopefully resolve the issue. ${ }^{1,2}$ Although these trials have closed to accrual and the surgical morbidity and mortality have been reported, the survival results are not yet mature. As such, surgeons are left with older results from the Lung Cancer Study Group and with retrospective analyses and reviews of large national databases to inform their opinions regarding the

Scanning this QR code will take you to the article title page to access supplementary information. To view the AATS Annual Meeting Webcast, see the URL next to the webcast thumbnail.

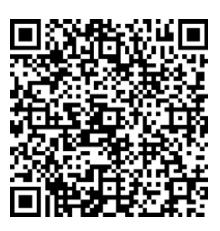




\section{Abbreviations and Acronyms \\ CSS = cancer-specific survival \\ NSCLC $=$ non-small cell lung cancer \\ OS $\quad=$ Overall survival \\ SEER = Surveillance, Epidemiology, and End Results Program \\ SLR = sublobar resection}

long-term equivalency of SLR..$^{3-7}$ These studies generally demonstrate that SLR is inferior to lobectomy. Certainly tumor factors, including size, radiologic features, and histologic subtype play a role in the outcomes following SLR. It has also become clear that surgical quality measures, including preoperative staging, surgical margins, and lymph node dissection play a role in determining longterm survival following lung cancer resection. ${ }^{8-11}$

The role of lymph node dissection in SLR is of particular interest because previous studies have suggested that lymph nodes are frequently not removed during SLR. ${ }^{8,12-15}$ For patients undergoing lobectomy for NSCLC, an increased number of lymph nodes removed has been associated with a survival benefit, which is reflected in guidelines regarding lymphadenectomy issued by several societies, including the International Association for the Study of Lung Cancer, the American College of Surgeons, and the National Comprehensive Cancer Network. ${ }^{16-18}$ However, most of these recommendations are based primarily on patients undergoing lobectomy and do no specifically address the role of lymphadenectomy in SLR. In a previous publication from our institutional database, we demonstrated that clinical stage I NSCLC patients undergoing wedge resection who had lymph node sampling had lower locoregional recurrence than patients without lymph node sampling. ${ }^{12}$ Similarly, 2 recent publications evaluating patients undergoing SLR in the Surveillance, Epidemiology, and End Result Program (SEER) database demonstrated that greater numbers of lymph nodes examined were associated with improved survival. ${ }^{19,20}$ After excluding patients without any lymph nodes examined, the extent of resection (either wedge resection or segmentectomy) was no longer a factor in predicting outcome. ${ }^{19}$ Similarly, we sought to determine how lymph node dissection and examination might modulate the comparative effectiveness of SLR versus lobectomy in NSCLC patients using the SEERMedicare database. We elected to confine our analysis to stage I patients with tumors $\leq 2 \mathrm{~cm}$, similar to those patients evaluated in randomized trials.

\section{METHODS}

\section{Data Source and Study Population}

We used the SEER and Medicare linked data. Linkage between SEER registry and Medicare claims is achieved for more than $90 \%$ of patients.
SEER identifies $28 \%$ of all incident cancer cases in the United States, and Medicare insures approximately $97 \%$ of all Americans aged $\geq 65$ years. $^{21}$

We identified Medicare beneficiaries with primary NSCLC, who underwent lobectomy or SLR between October 1, 2007, and June 30, 2012, from the linked database. These years were chosen because many of the detailed International Classification of Diseases-Ninth Revision-Clinical Modification codes become available on October 1,2007. We restricted to patients with pathologic stage I disease and tumor size $\leq 2 \mathrm{~cm}$ and further excluded those without pathologic confirmation. Patients with missing tumor stage or tumor size were thus not included. To ensure completeness of data to ascertain comorbitites within 1 year before the procedure, only patients who were aged 66 years or older at the time of the surgery and continuously enrolled in Medicare Part A and Part B and not enrolled in a health maintenance organization in the year before the procedure were included in the final cohort (Figure 1).

\section{Exposure and Outcomes}

The exposure variable was surgical procedure, comparing lobectomy to SLR. For the majority of the analysis, wedge resection and segmentectomy were grouped together as SLR based on the trial design of Cancer and Leukemia Group B 140503. Our primary outcome of interest was overall survival (OS). Secondary outcome was cancer-specific survival (CSS). OS was defined as time until death from any cause, with patients censored at the end of the study (December 31, 2013). SEER provides information about disease-specific cause of death, allowing us to determine CSS. CSS was defined as time to death from lung cancer, with patients censored at the end of 2011 (up until which cause of death information was available) or at the time of a nondisease-related death, whichever came earlier. Mean follow-up for overall survival was 3.3 years (range, $0-6.25$ years), and mean follow-up for CSS was 1.9 years (range, 0-4.25 years).

\section{Covariates}

Patient sociodemographic characteristics examined were age at surgery, sex, race, marital status, residence (metropolitan or nonmetropolitan), census tract education level, and census tract median income level. Tumor characteristics examined were $\mathrm{T}$ classification ( $\mathrm{T} 1$ or $\mathrm{T} 2$ ), histology (adenocarcinoma, squamous, or other), grade, size, and lymph nodes examined (based on the pathology counts). The uses of preoperative computed tomography and positron-emission tomography scans were determined with procedure codes from Medicare claims data. Patients' comorbidities within 1 year before the procedure was ascertained using previously validated Elixhauser comorbidities index..$^{22}$ Procedure characteristics included the use of video-assisted thoracic surgery, hospital and surgeon volume, and surgeon specialty. Surgeon volume was calculated based on encrypted surgeon identifiers associated with the procedure claim. When a surgery was recorded to have been performed by 2 surgeons, this particular case was counted toward the volumes of both surgeons. When a surgery was recorded to have been performed by 1 primary surgeon and 1 assistant, this case was counted toward the volume of the primary surgeon. A missing category was created for variables with missing values.

\section{Statistical Analysis}

Propensity-score matching were separately performed to account for differences in characteristics between the lobectomy and SLR groups. A propensity score for receiving SLR was created using a logistic regression based on potential confounding variables, including sociodemographic characteristics, comorbidities, tumor characteristics, preoperative computed tomography and positron-emission tomography scan use, and procedure-related variables. Number of lymph nodes examined and cancer occurrence afterward were not preoperative variables and thus were not used in propensity-score matching. A balanced cohort was then created using a 1-to-1 nearest neighbor matching algorithm. The logit of the 

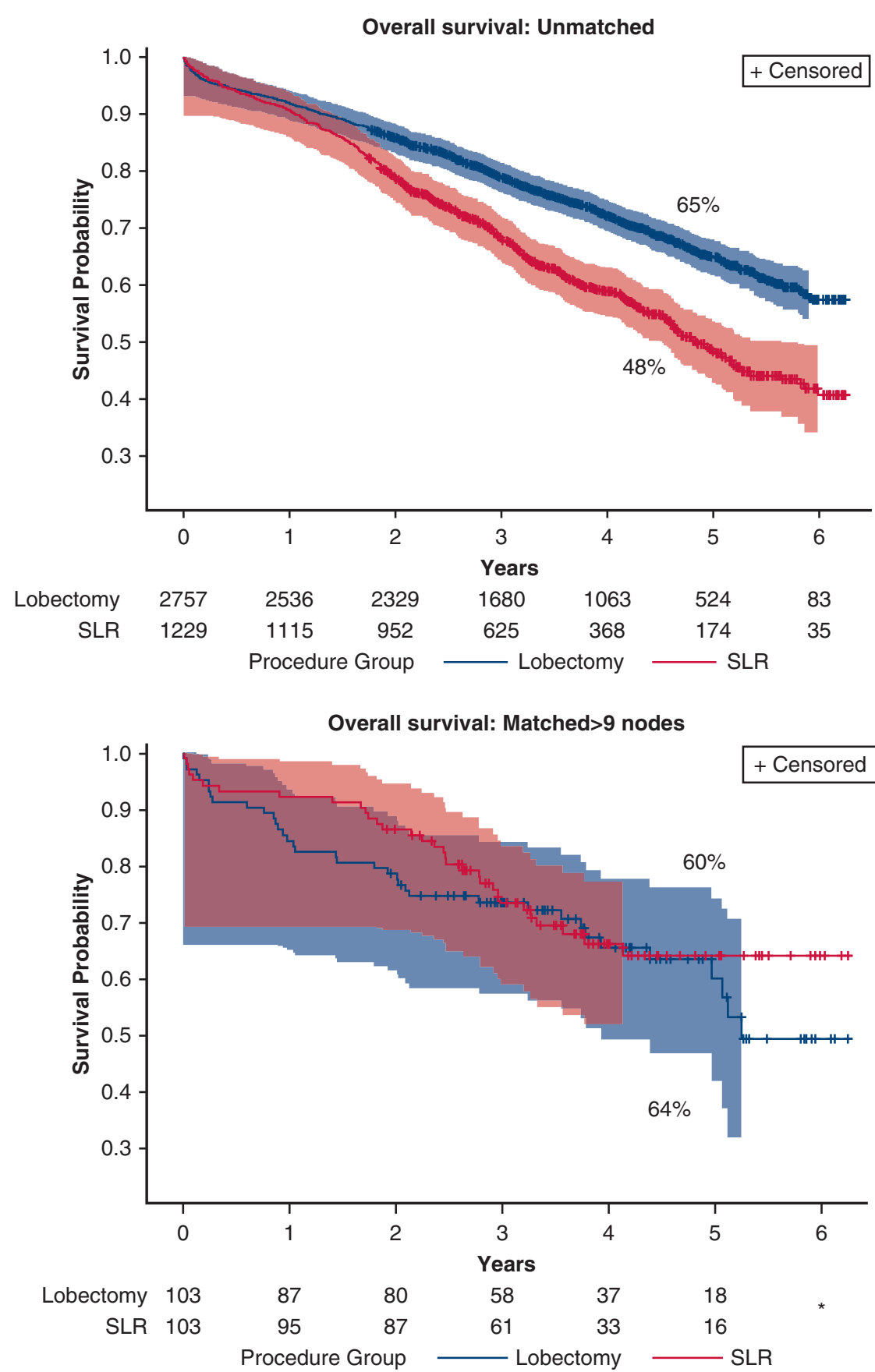

FIGURE 1. Identification of patients for inclusion from the Surveillance, Epidemiology and End Results Program-Medicare database between 2007 and 2012. SLR, Sublobar resection.

propensity score was used for matching, with a caliper width of 0.2 times its standard deviation as recommended by Austin. ${ }^{23}$

Cohort characteristics before matching was compared using Student $t$ tests for continuous variables and $\chi^{2}$ tests for categorical variables. Balances in characteristics before and after propensity-score matching were assessed using absolute difference. Kaplan-Meier curves were constructed with $95 \%$ Hall-Wellner confidence bands to examine OS and CSS. Estimated 5-year OS and 4-year CSS were obtained. Differences in OS and CSS following lobectomy and SLR were assessed using a Cox proportional hazard model, with a robust sandwich variance to account for matched data. The proportional hazards assumption was tested to confirm the adequacy of the model.

To further evaluate survival following lobectomy and SLR related to the extent of lymphadenectomy, we performed 2 subgroup analyses. The first subgroup analysis was performed among patients who had at least 1 lymph node examined during their surgery. The second analysis was performed among patients who had at least 9 lymph nodes examined during their surgery. The cutpoint of 9 was chosen based on the observed relationship 


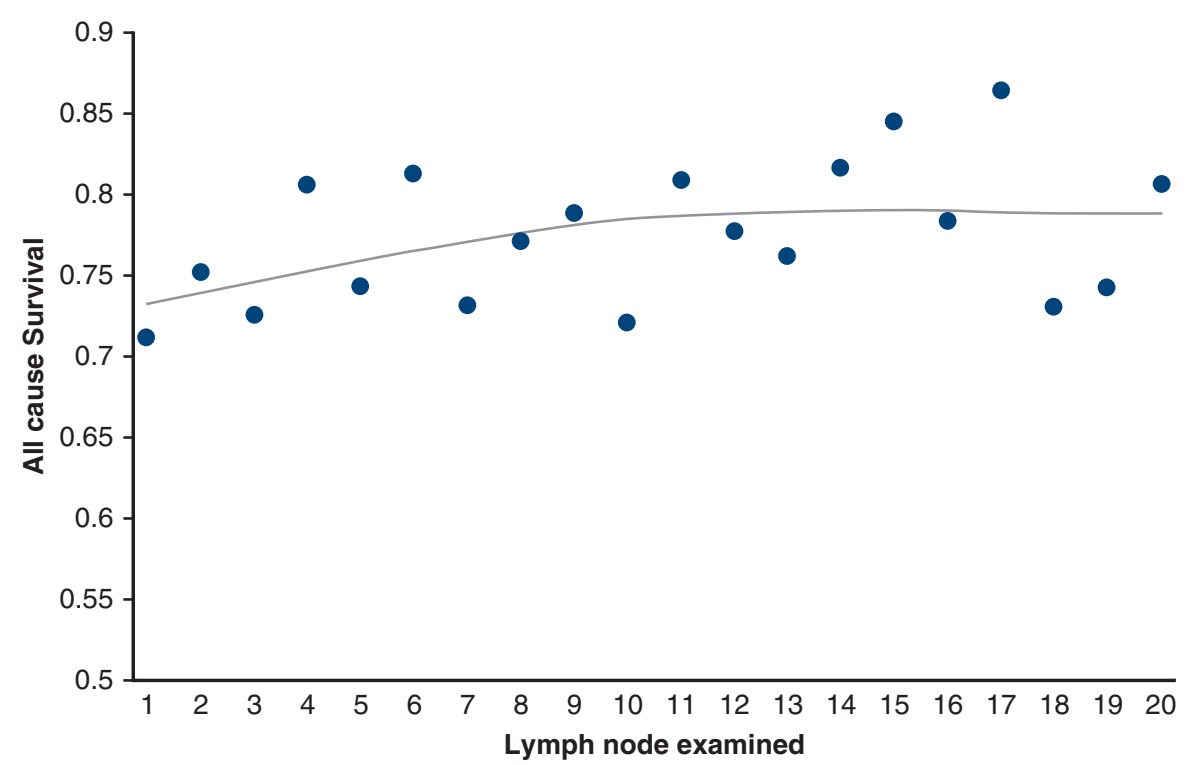

FIGURE 2. Survival increased with increasing numbers of lymph nodes examined. Using node counts as cutpoints and piecewise cox regression, a cutpoint of 9 was selected as the most discriminatory based on the lowest Akaike information criterion.

between number of lymph nodes examined and survival in our cohort. We first evaluated survival at 3 years predicted by number of lymph nodes examined graphically, and observed an inverse relationship between them. Survival improved with increased number of lymph nodes examined, with a plateau appearing around 8 to 10 lymph nodes examined. We then fitted a piecewise Cox regression using these 3 numbers as cutpoints, and a cutpoint of 9 was selected based on lowest Akaike information criterion (Figure 2).

For each subgroup analysis, a separate propensity-score matching was conducted and comparisons of OS and CSS were made using created cohorts. Similar statistical procedures were used in the subgroup analyses as described above. All analyses were carried out using SAS version 9.3 (SAS Institute, Inc. Cary, NC).

\section{RESULTS}

\section{Main Analysis}

For the time period studied (October 2007-June 2012), we identified 36,104 patients in the SEER-Medicare database undergoing resection for lung cancer. After defining the cohort by prespecified demographic and tumor characteristics, there remained 2757 patients undergoing lobectomy and 1229 patients undergoing SLR for stage I tumors $\leq 2 \mathrm{~cm}$ (Figure 1). Among these 1229 patients undergoing SLR were 998 patients undergoing wedge resection and 231 patients undergoing segmentectomy. Demographic characteristic differences between the 2 groups of patients are presented in Table 1. Most notably, SLR patients were older with more comorbidities and more prior cancers, were less likely to have had a preoperative positron-emission tomography scan, and were less likely to have had adenocarcinoma. Differences between the 2 groups were marked with regard to extent of lymph node dissection and evaluation (Table 1). Among patients undergoing lobectomy, $94.7 \%$ of patients had lymph nodes examined compared with only $52.2 \%$ of patients undergoing SLR. The majority of lobectomy patients had 6 or more lymph nodes examined $(55.9 \%)$, compared with only $14.0 \%$ of patients undergoing SLR $(P<.001)$. Among those undergoing SLR, patients undergoing segmentectomy $(\mathrm{n}=231)$ were more likely to have any lymph nodes examined than were patients undergoing wedge resection $(\mathrm{n}=998)$ $(67 \%$ vs $49 \% ; P<.01)$.

There was no difference in survival among patients undergoing wedge resection versus those undergoing segmentectomy (hazards [HR], 0.97; 95\% confidence interval [CI], 0.77-1.23). As such, these patients were grouped together for analysis. In the entire cohort, 798 patients undergoing lobectomy and 515 patients undergoing SLR died during follow-up, with estimated 5-year OS of $65 \%$ and $48 \%$, respectively, whereas CSS at 4 years was $90.8 \%$ and $82.8 \%$, respectively (Figure 3, $A$ and $B$ ). The propensityscore matched cohort consisted 1124 pairs of patients. Cohort characteristics were balanced between the 2 groups after matching (Table 1 and Table E1). In the matched cohort, OS at 5 years was $62 \%$ versus $49 \%(P<.001)$ and CSS at 4 years was $93 \%$ versus $82 \%(P<.0010)$, favoring lobectomy over SLR (Figure 3, $C$ and $D$ ). Without accounting for lymph nodes examined, SLR was associated with a $50 \%$ increase in the risk all-cause death (HR, 1.48; $95 \%$ CI, $1.29-1.69)$ and a $100 \%$ increase in the risk of CSS (HR, 2.05; 95\% CI, 1.40-3.01).

\section{Subgroup Analysis}

Subgroup analyses were conducted among patients with at least 1 lymph node examined and among those with 9 or 
TABLE 1. Balance in characteristics before and after propensity-score matching. Matching was conducted without considering lymph nodes examined

\begin{tabular}{|c|c|c|c|c|c|c|}
\hline \multirow[b]{2}{*}{ Characteristic } & \multicolumn{3}{|c|}{ Full cohort } & \multicolumn{3}{|c|}{ Matched cohort } \\
\hline & $\begin{array}{l}\text { Lobectomy } \\
(n=2757)\end{array}$ & $\begin{array}{c}\text { SLR } \\
(n=1229)\end{array}$ & $P$ value & $\begin{array}{r}\text { Lobectomy } \\
(n=1124)\end{array}$ & $\begin{array}{c}\text { SLR } \\
(\mathrm{n}=\mathbf{1 1 2 4})\end{array}$ & $P$ value \\
\hline \multicolumn{7}{|l|}{ Demographic } \\
\hline Age (y) & $74.3 \pm 5.5$ & $75.6 \pm 5.7$ & $<.001$ & $75.1 \pm 5.8$ & $75.3 \pm 5.6$ & .55 \\
\hline Male & $1196(43.4)$ & $498(40.5)$ & .09 & 445 (39.6) & $458(40.7)$ & .58 \\
\hline White race & $2488(90.2)$ & $1131(92.0)$ & .07 & $1039(92.4)$ & $1032(91.8)$ & .58 \\
\hline \multicolumn{7}{|l|}{ Tumor variables } \\
\hline $\mathrm{T} 1$ & $2362(85.7)$ & $1021(83.1)$ & .03 & $937(83.4)$ & $935(83.2)$ & .91 \\
\hline Histology & & & .001 & & & .75 \\
\hline Adenocarcinoma & $1427(51.8)$ & $562(45.7)$ & & $520(46.3)$ & 527 (46.9) & \\
\hline Squamous & $704(25.5)$ & $370(30.1)$ & & $328(29.2)$ & $326(29.0)$ & \\
\hline Other & $626(22.7)$ & $297(24.2)$ & & $276(24.6)$ & $271(24.1)$ & \\
\hline Size $(\mathrm{cm})$ & $1.5 \pm 0.4$ & $1.4 \pm 0.4$ & $<.001$ & $1.4 \pm 0.4$ & $1.4 \pm 0.4$ & .88 \\
\hline \multicolumn{7}{|l|}{ Preoperative variables } \\
\hline Preoperative CT scan & $2307(83.7)$ & $1005(81.8)$ & .14 & $918(81.7)$ & $922(82.0)$ & .82 \\
\hline Preoperative PET scan & $2196(79.7)$ & $899(73.1)$ & $<.001$ & $835(74.3)$ & $837(74.5)$ & .92 \\
\hline Number of comorbidities & & & .004 & & & .74 \\
\hline $0-2$ & $618(22.4)$ & $238(19.4)$ & & $220(19.6)$ & $224(19.9)$ & \\
\hline $3-5$ & $1384(50.2)$ & $595(48.4)$ & & $546(48.6)$ & $549(48.8)$ & \\
\hline $6+$ & $755(27.4)$ & $396(32.2)$ & & $358(31.9)$ & $351(31.2)$ & \\
\hline \multicolumn{7}{|l|}{ Procedural } \\
\hline Year of procedure & & & .16 & & & .38 \\
\hline 2007-2008 & 809 (29.3) & $388(31.6)$ & & $351(31.2)$ & 359 (31.9) & \\
\hline $2009-2010$ & $1311(47.6)$ & $545(44.3)$ & & $492(43.8)$ & $507(45.1)$ & \\
\hline 2011-2012 & $637(23.1)$ & $296(24.1)$ & & $281(25.0)$ & $258(23.0)$ & \\
\hline VATS & $1358(49.3)$ & $801(65.2)$ & $<.001$ & $698(62.1)$ & 705 (62.7) & .74 \\
\hline Surgeon volume & & & $<.001$ & & & .65 \\
\hline Tertile 1 & $866(31.4)$ & $332(27.0)$ & & $292(26.0)$ & $303(27.0)$ & \\
\hline Tertile 2 & $858(31.1)$ & $364(29.6)$ & & $321(28.6)$ & $315(28.0)$ & \\
\hline Tertile 3 & $910(33.0)$ & $428(34.8)$ & & $412(36.7)$ & $411(36.6)$ & \\
\hline Missing & $123(4.5)$ & $105(8.5)$ & & $99(8.8)$ & $95(8.5)$ & \\
\hline \multicolumn{7}{|l|}{ Postoperative variables* } \\
\hline LNs examined & & & $<.001$ & & & $<.001$ \\
\hline Not examined & $145(5.3)$ & $588(47.9)$ & & $72(6.4)$ & $527(46.9)$ & \\
\hline $1-4$ & 652 (23.7) & $370(30.1)$ & & $262(23.3)$ & 347 (30.9) & \\
\hline $5-8$ & $697(25.3)$ & $95(7.7)$ & & $270(24.0)$ & 87 (7.7) & \\
\hline$\geq 9$ & $1049(38.1)$ & $104(8.5)$ & & $418(37.2)$ & $95(8.5)$ & \\
\hline Unknown & $210(7.6)$ & $71(5.8)$ & & $101(9.0)$ & $67(6.0)$ & \\
\hline
\end{tabular}

Values are presented as mean \pm standard deviation or $\mathrm{n}(\%)$. SLR, Sublobar resection; $C T$, computed tomography; PET, positron-emission tomography; VATS, video-assisted thoracic surgery; $L N$, lymph nodes. *These were not presurgical variables and therefore not matched. Frequencies were examined between groups.

more lymph nodes examined. Propensity-score matching was conducted for these 2 groups separately, and resulted in 569 and 103 pairs of patients in the matched cohorts, respectively (Table 2).

For matched patients with any lymph nodes resected and examined, survival differences still existed, favoring lobectomy. SLR was associated with worse OS (HR, 1.38; 95\% CI, 1.12-1.69) and CSS (HR, 1.62; 95\% CI, 1.00-2.64), with an absolute OS at 5 years of $55 \%$ compared with $65 \%$ for lobectomy (Figure $4, A$ and $B)(P=.002)$. Finally, in the matched cohort of patients with 9 or more lymph nodes resected and examined ( 75 patients with wedge resection and 28 with segmentectomy among SLR group), differences in survival ceased to exist. For these patients, SLR had equivalent OS (HR, 0.84; 95\% CI, 0.50-1.39) and CSS (HR, 1.10 ; 95\% CI, 0.35-3.44) to lobectomy. In those cohorts, 5 year OS was $64 \%$ for SLR and $60 \%$ for lobectomy (Figure 4, $C$ and $D$ ). The method of SLR, segmentectomy versus wedge resection, had no effect on overall survival by multivariable analysis (HR, 0.97; 95\% CI, 0.77-1.23). 

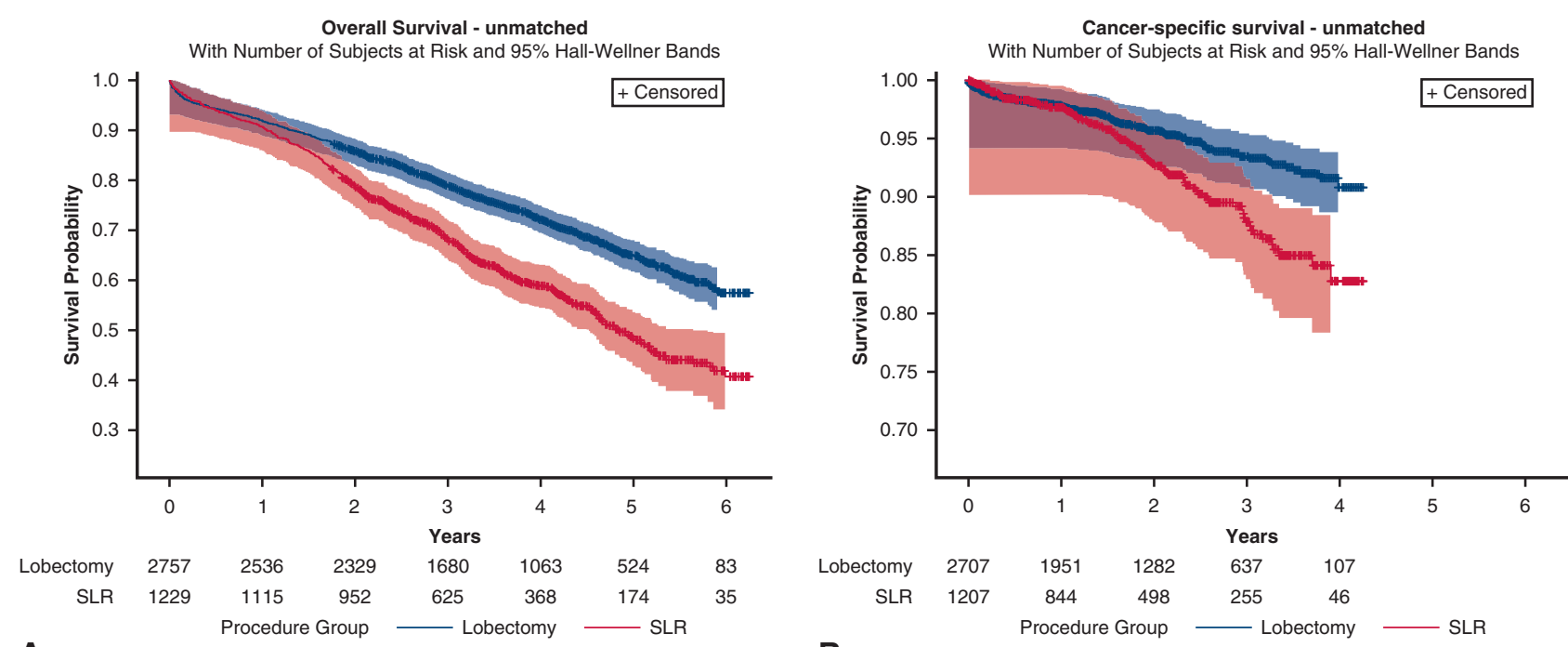

A

B
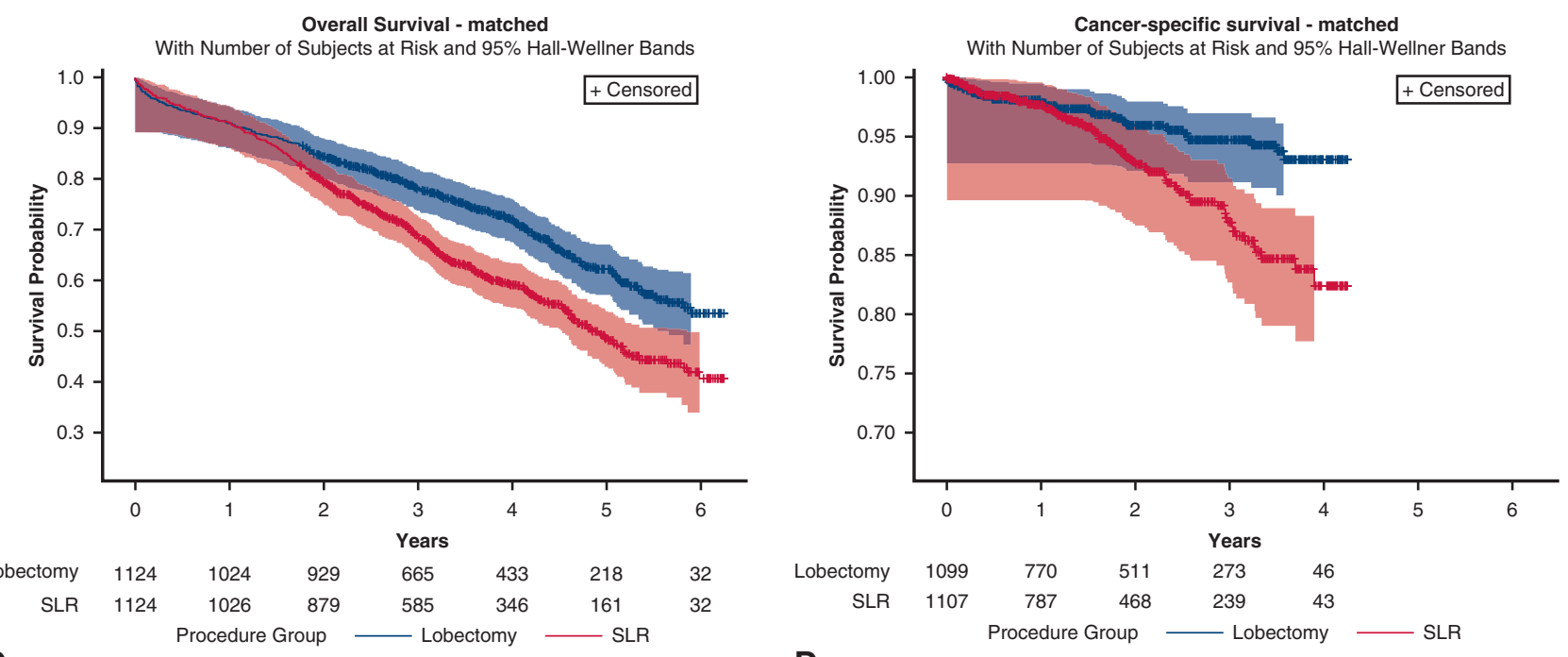

C

D

FIGURE 3. Overall survival and cancer-specific survival following lobectomy and sublobar resection (SLR) for lung cancer with tumor size $\leq 2 \mathrm{~cm}$ among Medicare beneficiaries. A and B, Before propensity-score matching. C and D, After propensity-score matching. Matching conducted without considering lymph nodes examined.

\section{DISCUSSION}

In the current study, we found that in pathologically staged NSCLC patients with tumors $\leq 2 \mathrm{~cm}$, SLR leads to fewer lymph nodes removed and is associated with inferior survival compared with lobectomy. This survival difference between SLR and lobectomy is consistent with previous analyses from large administrative databases. ${ }^{6,7}$ The frequent failure of surgeons to assess lymph nodes during SLR has been well documented. In large institutional series and in the National Cancer Database, the proportion of patients undergoing SLR with no lymph nodes assessed ranged from $29 \%$ to $68 \%{ }^{12,13,15,19,20}$ Even in a well-controlled prospective surgical trial, American College of Surgeons
Oncology Group Z4032, designed to specifically evaluate surgical outcomes, $28 \%$ of patients undergoing wedge resection had no lymph nodes sampled. ${ }^{24}$ It is therefore perhaps not surprising that in the current analysis from the SEER-Medicare database, among the entire cohort of patients with stage I cancers $\leq 2 \mathrm{~cm}$ undergoing SLR, $47.8 \%$ of patients had no lymph nodes assessed.

Despite underuse, a more extensive lymphadenectomy appears to provide a protective effect for patients undergoing SLR and is associated with equivalent survival between matched patients undergoing SLR and lobectomy. This is consistent with previous analyses. Using the SEER database, Ludwig and colleagues ${ }^{8}$ found that an increased 
TABLE 2. Balance in characteristics after propensity-score matching among subgroup of patients with at least 1 lymph node (LN) examined and with $\geq 9$ LNs examined

\begin{tabular}{|c|c|c|c|c|c|c|}
\hline \multirow[b]{2}{*}{ Characteristic } & \multicolumn{3}{|c|}{$\begin{array}{l}\text { Matched cohort: } \\
\text { Any nodes examined }\end{array}$} & \multicolumn{3}{|c|}{$\begin{array}{l}\text { Matched cohort: } \\
\geq 9 \text { LNs examined }\end{array}$} \\
\hline & $\begin{array}{l}\text { Lobectomy } \\
(n=564)\end{array}$ & $\begin{array}{c}\text { SLR } \\
(n=564)\end{array}$ & Difference & $\begin{array}{l}\text { Lobectomy } \\
(n=103)\end{array}$ & $\begin{array}{c}\text { SLR } \\
(\mathbf{n}=\mathbf{1 0 3})\end{array}$ & Difference \\
\hline \multicolumn{7}{|l|}{ Demographic } \\
\hline Age (y) & $74.9 \pm 5.3$ & $74.9 \pm 5.5$ & 0.76 & $74.4 \pm 5.0$ & $74.2 \pm 5.3$ & 0.78 \\
\hline Male & $228(40.4)$ & $226(40.1)$ & 0.9 & $42(40.8)$ & $39(37.9)$ & 0.65 \\
\hline White race & $501(88.8)$ & 507 (89.9) & 0.55 & $98(95.1)$ & $91(88.3)$ & .07 \\
\hline Married & $290(51.4)$ & $278(49.3)$ & 0.82 & $56(54.4)$ & $51(49.5)$ & 0.82 \\
\hline \multicolumn{7}{|l|}{ Tumor variables } \\
\hline $\mathrm{T} 1$ & $460(81.6)$ & $465(82.4)$ & 0.68 & $92(89.3)$ & $93(90.3)$ & 0.82 \\
\hline Adenocarcinoma & $262(46.5)$ & $270(47.9)$ & 0.5 & $52(50.5)$ & $46(44.7)$ & 0.2 \\
\hline Size $(\mathrm{cm})$ & $1.5 \pm 0.4$ & $1.5 \pm 0.4$ & 0.85 & $1.5 \pm 0.4$ & $1.5 \pm 0.5$ & 0.99 \\
\hline \multicolumn{7}{|l|}{ Preoperative variables } \\
\hline Preoperative CT scan & $470(83.3)$ & $468(83.0)$ & 0.88 & $94(91.3)$ & $90(87.4)$ & 0.32 \\
\hline Preoperative PET scan & $434(77.0)$ & $434(77.0)$ & 0.99 & $90(87.4)$ & $89(86.4)$ & 0.83 \\
\hline Number of comorbidities & & & 0.9 & & & 0.85 \\
\hline $0-2$ & $134(23.8)$ & $125(22.2)$ & & 19 (18.4) & $21(20.4)$ & \\
\hline $3-5$ & $262(46.5)$ & $277(49.1)$ & & $55(53.4)$ & 49 (47.6) & \\
\hline $6+$ & $168(29.8)$ & $162(28.7)$ & & $29(28.2)$ & $33(32.0)$ & \\
\hline Prior other primary cancer & $162(28.7)$ & $157(27.8)$ & 0.74 & $29(28.2)$ & $33(32.0)$ & 0.53 \\
\hline \multicolumn{7}{|l|}{ Procedural } \\
\hline Year of procedure & & & 0.54 & & & 0.83 \\
\hline 2007-2008 & $198(35.1)$ & $186(33.0)$ & & $28(27.2)$ & $30(29.1)$ & \\
\hline $2009-2010$ & $240(42.6)$ & $249(44.1)$ & & $54(52.4)$ & $52(50.5)$ & \\
\hline 2011-2012 & $126(22.3)$ & $129(22.9)$ & & $21(20.4)$ & $21(20.4)$ & \\
\hline VATS & $353(62.6)$ & $338(59.9)$ & 0.33 & $70(68.0)$ & $69(67.0)$ & 0.88 \\
\hline Facility volume & & & 0.59 & & & 0.77 \\
\hline $\mathrm{T} 1$ & $150(26.6)$ & $158(28.0)$ & & $20(19.4)$ & $20(19.4)$ & \\
\hline $\mathrm{T} 2$ & $183(32.4)$ & $181(32.1)$ & & $43(41.7)$ & $40(38.8)$ & \\
\hline $\mathrm{T} 3$ & $231(41.0)$ & $225(39.9)$ & & $40(38.8)$ & $43(41.7)$ & \\
\hline Surgeon volume & & & 0.58 & & & 0.88 \\
\hline $\mathrm{T} 1$ & $120(21.3)$ & $126(22.3)$ & & $21(20.4)$ & $22(21.4)$ & \\
\hline $\mathrm{T} 2$ & $167(29.6)$ & $170(30.1)$ & & $29(28.2)$ & $29(28.2)$ & \\
\hline $\mathrm{T} 3$ & $218(38.7)$ & $210(37.2)$ & & $33(32.0)$ & $32(31.1)$ & \\
\hline Surgeon SLR volume & & & 0.9 & & & 0.72 \\
\hline Tertile 1 & $103(18.3)$ & $103(18.3)$ & & $20(19.4)$ & $15(14.6)$ & \\
\hline Tertile 2 & $161(28.5)$ & $163(28.9)$ & & $20(19.4)$ & $26(25.2)$ & \\
\hline Tertile 3 & $241(42.7)$ & $240(42.6)$ & & $43(41.7)$ & $42(40.8)$ & \\
\hline Thoracic surgeon & $343(60.8)$ & $335(59.4)$ & 0.69 & $50(48.5)$ & $56(54.4)$ & 0.61 \\
\hline \multicolumn{7}{|l|}{ Postoperative variables* } \\
\hline LNs examined & & & $<0.001$ & & & - \\
\hline $1-4$ & $165(29.3)$ & $367(65.1)$ & & - & - & \\
\hline $5-8$ & $161(28.5)$ & $93(16.5)$ & & - & - & \\
\hline$\geq 9$ & $238(42.2)$ & $104(18.4)$ & & $100 \%$ & $100 \%$ & \\
\hline
\end{tabular}

Values are presented as mean \pm standard deviation or $\mathrm{n}(\%) . L N$, Lymph nodes; SLR, sublobar resection; CT, computed tomography; PET, positron-emission tomography; VATS, video-assisted thoracic surgery. ${ }^{*}$ These were not presurgical variables, and therefore not matched. Frequencies examined between groups.

number of lymph nodes removed and analyzed during lobectomy was associated with a statistically significant increase in survival. From the National Cancer Database, Gulack and colleagues ${ }^{15}$ demonstrated similar findings of a survival benefit related to lymphadenectomy for patients undergoing lobectomy, even for patients with tumors
$<2 \mathrm{~cm}$. Neither of these addressed the role of lymphadenectomy in SLR. However, Yendamuri and colleagues ${ }^{19}$ and Cao and colleagues ${ }^{20}$ recently published independent analyses of the SEER database, suggesting that lymph node examination was associated with significant improvements in survival for patients undergoing SLR as well. Yendamuri 


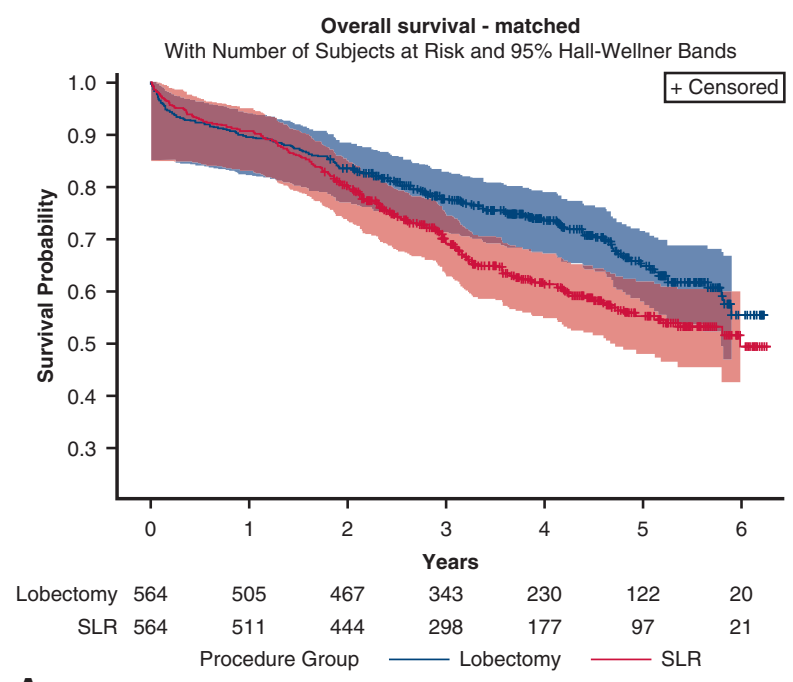

A

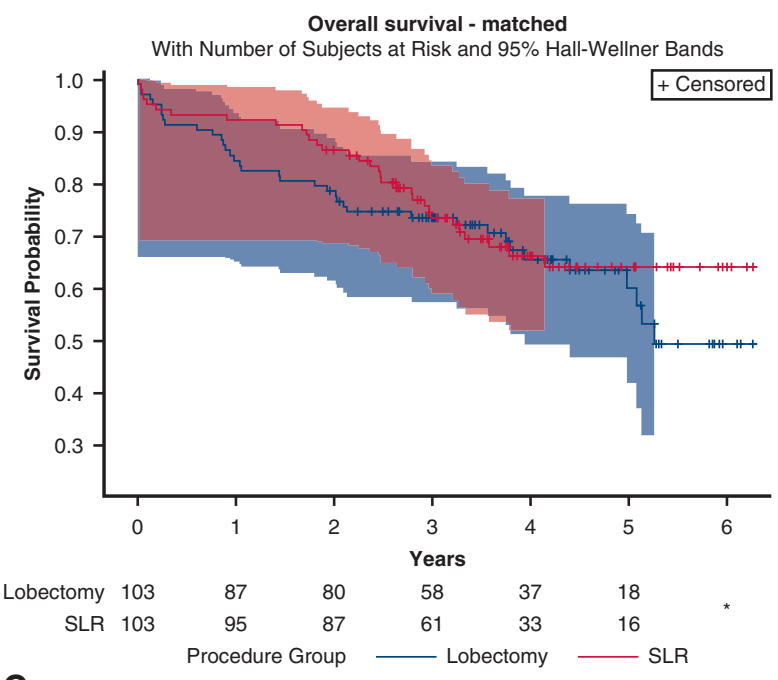

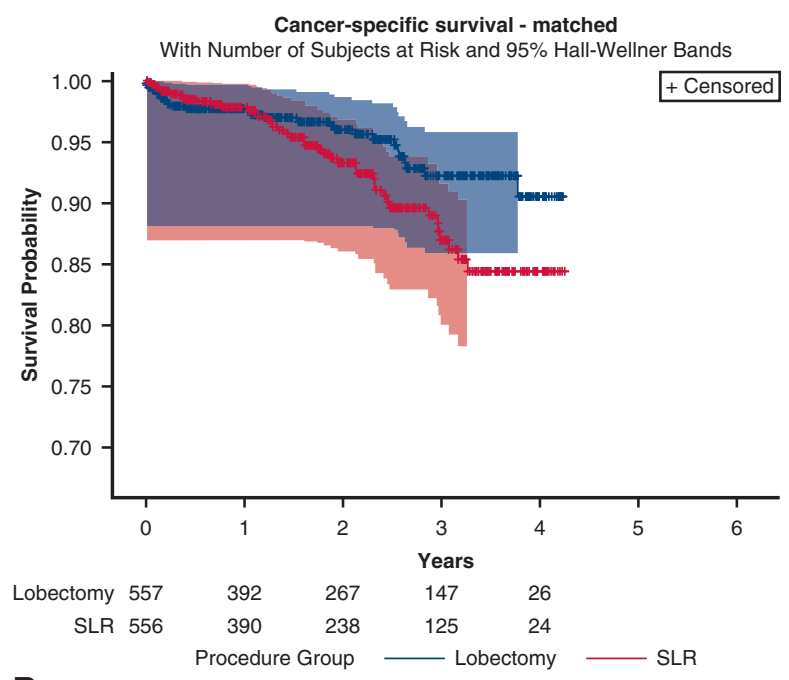

B

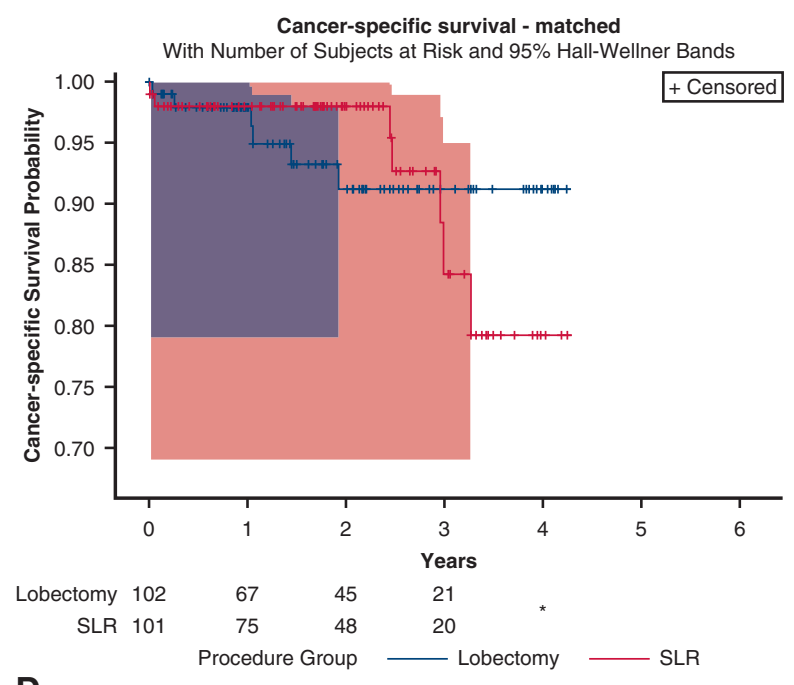

FIGURE 4. Subgroup analysis of overall survival and cancer-specific survival following lobectomy and sublobar resection (SLR) for lung cancer with tumor size $\leq 2 \mathrm{~cm}$ among Medicare beneficiaries after propensity-score matching. A and B, Patients with at least 1 lymph node examined. C and D, Patients with at least 9 lymph nodes examined.

and colleagues ${ }^{19}$ showed that survival increased with each increase in numbers (none, 1-3, 4-6, 7-9, and >9) of lymph nodes examined. The effect of lymph node examination had a stronger effect on survival than did the extent of resection, wedge versus segmentectomy. Additionally, from our own institutional database, we recently demonstrated that lymph node resection and assessment led to a higher freedom from locoregional recurrence at 5 years $(92 \%$ vs $74 \% ; P=.025)$ and a strong trend toward improved 5-year disease-free survival $(65 \%$ vs $40 \% ; P=.058)$ during wedge resection for clinical stage I NSCLC. ${ }^{12}$

In the current study, utilizing the SEER-Medicare database we sought to determine whether a more extensive lymphadenectomy could potentially mitigate any detrimental effects of SLR on survival compared with lobectomy. We found a relationship of increased lymphadenectomy to increased survival that plateaued around 9 lymph nodes examined. Although SLR was associated with worse survival in the SEER-Medicare cohort as a whole when compared with lobectomy, this difference was lessened when patients without lymph node dissection were excluded and disappeared completely when evaluating matched cohorts of patients with 9 or more lymph nodes resected and examined.

Several potential reasons could explain these findings. One possibility in a database of pathologically staged patients is through stage purification. Patients who have their lymph nodes examined are obviously more likely to have 
lymph node metastases found. The rate of occult nodal metastases in patients with clinical stage I NSCLC ranges from $4 \%$ to $12 \%$ in previous studies. ${ }^{25,26}$ Such patients with surgically detected lymph node metastases would not be included in the current cohort. However, it is likely that a similar proportion of patients undergoing SLR without lymph node dissection or with only limited node dissection had occult nodal metastases that were not identified. These patients, still entered into the database as pathologic stage I, obviously could be expected to do poorly and would likely bring down survival in the SLR group, given the overall lower number of lymph nodes evaluated than in the lobectomy group. Another possibility regarding the survival benefit of lymphadenectomy is that lymph node removal itself is associated with a better oncologic operation and with improved local control. Patients in the SLR group who had more lymph nodes removed were more likely to have had segmentectomy, which may be oncologcially superior to wedge resection. Lymph node removal itself may also lead to decreases in local recurrence through the removal of pathologically occult micrometastatic disease. Finally, as described previously, ${ }^{12}$ it is likely that we as surgeons may often determine the extent of resection and lymphadenectomy based on personal clinical judgment. Patients who we subjectively consider to be frail, at higher risk for death from competing causes, or unlikely to tolerate adjuvant therapy may be more likely to undergo wedge resection without nodal assessment. This could account for some of the differences in OS seen between groups of patients with and without lymph node resection, despite the fact that the groups appear well balanced for comorbidities and tumor factors.

The study has several limitations. First, such a study would ideally be performed on clinically rather than pathologically staged patients. However, complete clinical staging information is not routinely available in the SEER-Medicare database. Additionally, clinical staging is more heterogeneous than is pathologic staging and poses its own potential limitations. Second, although we initially found a large number of patients for analysis, this number steadily decreased in propensity-matched groups used to evaluate the independent effects of lymphadenectomy. Our statistical power for determining survival differences therefore became more limited in those groups of patients and it is likely the study is insufficiently powered to prove noninferiority. Our propensity matching was also unable to account for smoking history or pulmonary function (these data were not available), which also likely played a significant role in choice of procedure and likely affected survival. Additionally, because we grouped patients undergoing wedge resection and segmentectomy together, it is not clear that the finding of a protective effect of lymphadenectomy extends to both of those procedures. The role of wedge resection in particular needs to be better clarified. Finally, it is well understood that retrospective evaluation of data from administrative databases is no substitute for randomized clinical trials. However, it is unlikely that a clinical trial could ever be performed to answer this clinical question. Although we are unable to control for inherent selection biases that go into the surgical decision making for these patients, we do believe that by controlling for demographic- and tumor-related factors in propensity-matched groups we were able to minimize those biases to the best extent possible.

\section{CONCLUSIONS}

Our study demonstrated that removal and examination of lymph nodes during SLR is associated with improvements in survival for patients with NSCLC. Regardless of the reasons why there is a benefit, it is apparent that thoracic surgeons should perform a lymphadenectomy as part of SLR and insist that pathologists fully examine these nodes. Our ability to optimally stage patients and to obtain exquisite local and regional control even with SLR is what will distinguish surgical approaches from competing methods of local therapy such as stereotactic radiation therapy and radiofrequency ablation. A large balance of evidence now suggests that a more extensive lymphadenectomy is associated with improvements in survival following NSCLC resection, even for SLR. $8,10,11,19,20$

\section{Webcast}

You can watch a Webcast of this AATS meeting presentation by going to: https://aats.blob.core.windows.net/ media/18Apr30/25ABC\%202.General\%20Thoracic $\% 20$ SS/S72\%20-\%20Part\%202/S72_3_webcast_043439559. mp4.

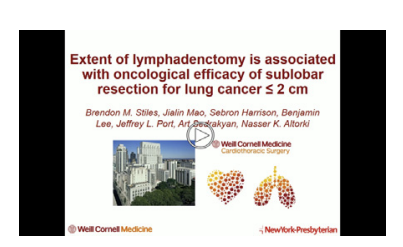

\section{Conflict of Interest Statement}

Dr Stiles has served on advisory boards for Merck and AstraZeneca. He is on the Board of the Lung Cancer Research Foundation. His wife receives stock and salary from Pfizer and PPD. All other authors have nothing to disclose with regard to commercial support.

\section{References}

1. Kohman LJ, Gu L, Altorki N, Scalzetti E, Veit LJ, Wallen JM, et al. Biopsy first: lessons learned from cancer and leukemia group B (CALGB) 140503. J Thorac Cardiovasc Surg. 2017;153:1592-7.

2. Nakamura K, Saji H, Nakajima R, Okada M, Asamura H, Shibata T, et al. A phase III randomized trial of lobectomy versus limited resection for small-sized 
peripheral non-small cell lung cancer (JCOG0802/WJOG4607L). Jpn J Clin Oncol. 2010;40:271-4.

3. Ginsberg RJ, Rubinstein L. The comparison of limited resection to lobectomy for T1N0 non-small cell lung cancer. LCSG 821. Chest. 1994;106(6 Suppl):318S-9S.

4. Schuchert MJ, Abbas G, Awais O, Pennathur A, Nason KS, Wilson DO, et al. Anatomic segmentectomy for the solitary pulmonary nodule and early-stage lung cancer. Ann Thorac Surg. 2012;93:1780-5.

5. Nomori H, Mori T, Ikeda, Yoshimoto K, Iyama K, Suzuki M. Segmentectomy for selected cT1N0M0 non-small cell lung cancer: a prospective study at a single institute. J Thorac Cardiovasc Surg. 2012;144:87-93.

6. Subramanian M, McMurry T, Meyers BF, Puri V, Kozower BD. Long-term results for clinical stage Ia lung cancer-comparing lobectomy and sublobar resection. Ann Thorac Surg. 2018;106:375-81.

7. Dai C, Shen J, Ren Y, Zhong S, Zheng H, He J, et al. Choice of surgical procedure for patients with non-small-cell lung cancer $\leq 1 \mathrm{~cm}$ or $\geq 1$ to $2 \mathrm{~cm}$ among lobectomy, segmentectomy, and wedge resection: a population-based study. J Clin Oncol. 2012;34:3175-82.

8. Ludwig MS, Goodman M, Miller DL, Johnstone PA. Postoperative survival and the number of lymph nodes sampled during resection of node-negative non-small cell lung cancer. Chest. 2005;128:1545-50.

9. Cameron RB. Adherence to lung cancer surgical quality standards is critical for the survival of both our patients and our specialty. J Thorac Cardiovasc Surg. 2018;156:392-3.

10. Ajmani GS, Wang CH, Kim KW, Howington JA, Kratz SB. Surgical quality of wedge resection affects overall survival in patients with early stage non-small cell lung cancer. J Thorac Cardiovasc Surg. 2018;156:380-91.

11. Samson P, Crabtree T, Broderick S, Kreisel D, Krupnick AS, Patterson GA, et al. Quality measures in clinical stage I non-small cell lung cancer: improved performance is associated with improved survival. Ann Thorac Surg. 2017; 103:303-11.

12. Stiles BM, Kamel MK, Nasar A, Harrison S, Nguyen AB, Lee P, et al. The importance of lymph node dissection accompanying wedge resection for clinical stage IA lung cancer. Eur J Cardiothorac Surg. 2017;51:511-7.

13. Mohiuddin K, Haneuse S, Sofer T, Gill R, Jaklitsch MT, Colson YL, et al. Relationship between margin distance and local recurrence among patients undergoing wedge resection for small $(\leq 2 \mathrm{~cm})$ non-small cell lung cancer. $J$ Thorac Cardiovasc Surg. 2014;147:1169-75.

14. Speicher PJ, Gu L, Gulack BC, Wang X, D’Amico TA, Hartwig MG, et al. Sublobar resection for clinical stage IA non-small-cell lung cancer in the United States. Clin Lung Cancer. 2016;17:47-55.

15. Gulack BC, Yang CF, Speicher PJ, Meza JM, Gu L, Wang X, et al. The impact of tumor size on the association of the extent of lymph node resection and survival in clinical stage I non-small cell lung cancer. Lung Cancer. 2015;90:554-60.

16. Rami-Porta R, Wittekind C, Goldstraw P, International Association for the Study of Lung Cancer (IASLC) Staging Committee. Complete resection in lung cancer surgery: proposed definition. Lung Cancer. 2005;49:25-33.

17. Darling GE, Allen MS, Decker PA, Ballman K, Malthaner RA, Inculet RI, et al. Number of lymph nodes harvested from a mediastinal lymphadenectomy: results of the randomized, prospective American College of Surgeons oncology group Z0030 trial. Chest. 2011;139:1124-9.

18. NCCN Clinical Practice Guidelines in Oncology. Non-small cell lung cancer (v.2.2013). Available at: http://www.nccn.org/professionals/physician_gls/pdf/ nscl.pdf. Accessed May 1, 2016.

19. Yendamuri S, Dhillon SS, Groman A, Dy G, Dexter E, Picone A, et al. Impact of the number of lymph nodes examined on the survival of patients with stage I nonsmall cell lung cancer undergoing sublobar resection. J Thorac Cardiovasc Surg. 2018;156:394-402.

20. Cao J, Xu J, He Z, Yuan P, Huang S, Lv W, et al. Prognostic impact of lymphadenectomy on outcomes of sublobar resection for stage IA non-small cell lung cancer $\leq 2 \mathrm{~cm}$. J Thorac Cardiovasc Surg. 2018;156:796-805.e4.

21. Warren JL, Klabunde CN, Schrag D, Bach PB, Riley GF. Overview of the SEERMedicare data: content, research applications, and generalizability to the United States elderly population. Med Care. 2002;40(8 Suppl). IV-3-18.

22. Elixhauser A, Steiner C, Harris DR, Coffey RM. Comorbidity measures for use with administrative data. Med Care. 1998;36:8-27.

23. Austin PC. Optimal caliper widths for propensity-score matching when estimating differences in means and differences in proportions in observational studies. Pharmaceut Stat. 2011;10:150-61.

24. Kent M, Landreneau R, Mandrekar S, Hillman S, Nichols F, Jones D, et al. Segmentectomy versus wedge resection for non-small cell lung cancer in high-risk operable patients. Ann Thorac Surg. 2013;96:1747-54.
25. Stiles BM, Servais EL, Lee PC, Port JL, Paul S, Altorki NK. Point: clinical stage IA non-small cell lung cancer determined by computed tomography and positron emission tomography is frequently not pathologic IA non-small cell lung cancer: the problem of understaging. J Thorac Cardiovasc Surg. 2009;137:13-9.

26. Boffa DJ, Kosinski AS, Paul S, Mitchell JD, Onaitis M. Lymph node evaluation by open or video-assisted approaches in 11,500 anatomic lung cancer resections. Ann Thorac Surg. 2012;94:347-53.

Key Words: lung cancer screening, low-dose computed tomography, non-small cell lung cancer, minimally invasive surgery, sublobar resection

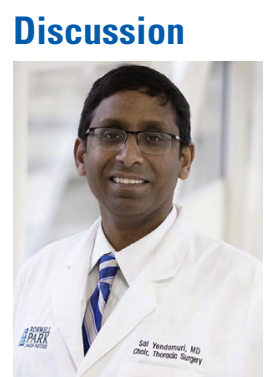

Dr Sai Yendamuri (Buffalo, NY). Thank you for the opportunity to discuss this paper, excellent work, Brendon, and thanks for sending me the manuscript well ahead of time. I have a few quick questions.

Why did you limit the time to 2012 , because that's already 6 years ago, and it may make a difference, because we are seeing more smaller cancers that are detected by lung screening and the biology of those cancers may be different. So would these results apply to practice today?

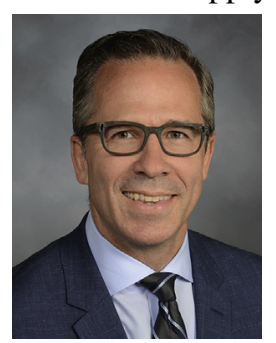

Dr Brendon Stiles (New York, NY). That's a great point. I'm going to be a little bit longer on this answer because it's very important. We started in 2007 just so that we could have the International Classification of Disease Ninth Revision codes, which changed then, to really get exquisite information to match the patients. We only had the database through 2013, so our follow-up was limited. But I think the point that you make is really critical and we are going to address this in the discussion that we really need to follow these patients longer.

In our wedge resection paper, the median time to recurrence was 18 months. We know from the Lung Cancer Study Group if you look back at those curves they really don't diverge until 3 to 4 years. So a major caveat of this study is that we have got to follow those patients longer. I think the same is true of the stereotactic body radiation therapy literature where really we have 3-year data but no 5-year data, anything on sublobar resection, where stereotactic body radiation therapy I think is going to need to stand the test of time.

Dr Yendamuri. So that actually answers another question, because the median time to overall survival that you looked at is 3.3 years and then cancer-specific survival was 1.9 years. So you do need more follow-up. 
The second question is: How was missing data handled, because the Surveillance, Epidemiology, and End Results database does have a lot of missing data. So was it just a case complete analysis, was this missing data imputation? If so, how did you do it?

Dr Stiles. I think our statisticians did missing data imputation. We had some trouble about that. Certainly we will have to go back and look at it more closely, I'm sure.

Dr Yendamuri. And the last question I have is you did allude to the fact that your propensity score matched analyses may not have power, because the last set that you alluded to equal only 100 pairs, and that may not be enough to show a difference. So a formal power calculation may benefit the paper.

Dr Stiles. I think that's a great point, Sai.

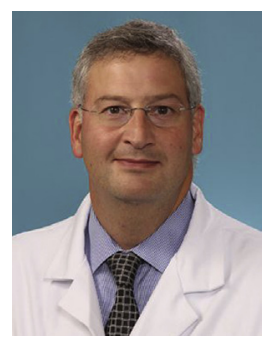

Dr Benjamin D. Kozower (St Louis, $M o$ ). Congratulations on a great study. I think you showed us the difference between effectiveness and efficacy. So your Cancer and Leukemia Group B study where it is prescribed and everyone has got to sample all the nodes, we are going to really know if these people are pathologic stage I. In the real world it does not happen. So our group is among those studies in press that you mentioned. There was a special study of the National Cancer Database that's not actually Surveillance, Epidemiology, and End Results Program data. But we showed the same thing. The median lymph node count in the sublobar group is 1 , and three quarters of those are wedge resections. And I'm guilty of the same thing at Wash U. We just looked at our own data, and when we do a wedge resection, we do not have 12 nodes.

So it's something we all have to deal with, and I think it's really important and as a quality measure going forward we are all moving toward outcomes measures and not process measures, but at some point we're really going to have to put this in.

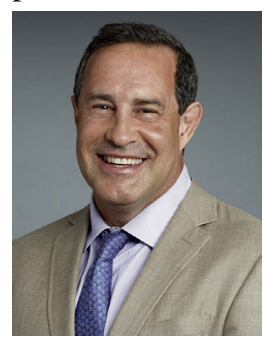

Dr Robert J. Cerfolio (New York, NY). It's not at some point. It was yesterday. It's embarrassing. If you want to be a radiologist, go do radiation oncology, but you should not let anybody out of the operating room without 10 or 15 lymph nodes. It's ludicrous. Response?

Dr Stiles. Great points.

Dr Cerfolio. We have been saying the same thing in this meeting for 10 years. It's just silly. If you don't want to be a surgeon, don't operate. If you are going to do a cancer operation, get at least 4 or $5 \mathrm{~N} 2$ stations and 1 or 2 or don't do the surgery, just be a psychiatrist.
Dr Stiles. And I would put in a plug for N1 stations, too. We often do a good job of picking out some N2 nodes when we do a wedge but really we probably need to do N1 nodes there as well.

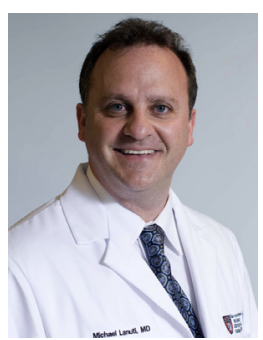

Dr Michael Lanuti (Boston, Mass). But, Brendon, you can't really say lymphadenectomy in your slide, right, you can't tell that from Surveillance, Epidemiology, and End Results Program data?

Dr Stiles. No, not at all, and if I said that, it's a mistake. It's lymph node examination we have tried to say.

That brings up a good point. Pathologic exam of lymph nodes versus surgical picking out lymph nodes, which I think is a another conversation.

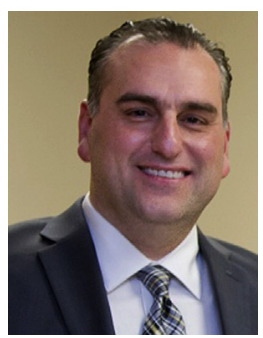

Dr Harmik J. Soukiasian (Los Angeles, Calif). That's the point that I was going to make is that inherently any sample that is a lobectomy versus a sublobar resection, the intralobar lymph nodes are also counted in the pathologic specimen. So I don't think you are able to tease out whether these were actual hilar N1 or N2 nodes that were dissected out versus the intralobar lymph node count that is going to be increased by pathologic examination of a lobe versus a segment.

Dr Cerfolio. But if the surgeon takes accountability in the operating room and marks them and makes the nurse record 1, you are going to get at least 1 or 210 's and a couple of in the 11's no matter what the segment is. You can always get a 10 .

Dr Soukiasian. Well, I know, but in general you have more intralobar nodes with a lobectomy specimen.

Dr Cerfolio. We agree, but it's incumbent on us to get at least a few if we are doing a segment.

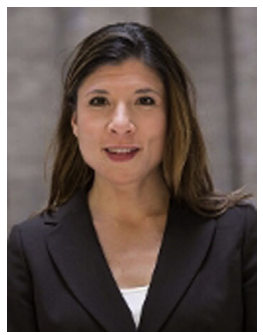

Dr Andrea Shari Wolf (New York, $N Y$ ). Thanks, Brendon, for a great talk. In 2012, Dr Swanson and I published a single-center study from a 2000 to 2005 data set from the Brigham and had similar findings, and there was outrage over a $50 \%$ rate of no lymph nodes sampled for the wedge resection group, mostly for the reasons you stated; that's the advantage of surgery over local therapies or stereotactic body radiation therapy. I was wondering if you can comment on how you thought a more updated data set might influence these results. You talked about long-term follow-up, but more importantly, has our practice changed since 2012 ? 
Dr Stiles. I remember that presentation. I remember the rate of no lymph nodes being a little higher, maybe, but I remember people were excited about it. I think that the randomized studies will show it; they are almost going to be too much. The problem with the American College of Surgeons Oncology Group Z0030 study is we probably did too good of a lymph node dissection there in the nondissection group. With these big databases it's really hard to figure some of this out. We can just see the relationship with number of nodes and not much beyond that.

Dr Wolf. And can I ask a corollary? I noticed there were a large number of sublobar resections with greater than nine nodes sampled, and I am concerned about the accuracy of that in a general data set like Surveillance, Epidemiology, and End Results data.

Dr Stiles. That's a great question, too. I think in Sai's article that is getting ready to come out that is online, he hypothesized that those patients with lots of lymph nodes might have more of an immunologic response. I think certainly in some patients we find lots of lymph nodes and it's hard to know who those patients are. It seems like a lot.

Dr Wolf. Were they wedges who became lobectomies?

Dr Stiles. No. Those were excluded.

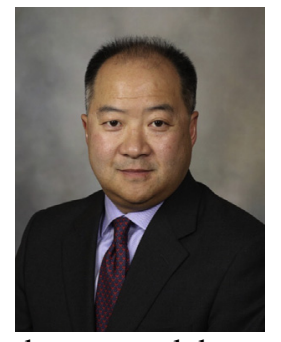

Dr Robert Shen (Rochester, Minn). Brendon, you had among your conclusions that the increase in lymphadenectomy is protective. One potential alternative explanation is that patients who had more lymph nodes you found lymph nodes that were positive and those patients then received adjuvant therapy, and that may then account for the $8 \%$ to $10 \%$ difference in survival, because that's what we would expect for patients who have adjuvant therapy with nodal positive disease.

Do you have the ability from your data to tell what percentage of lymph nodes were positive and what percentage of patients received adjuvant therapy as a potential alternative explanation that it's somehow protective to take the lymph node out?

Dr Stiles. You are on the right track to the alternative explanation I propose in the article. In this study, none of these patients had positive nodes; we excluded all those. It was pathologic staging. But certainly there should be a proportion of no lymph nodes sampled patients who probably had nodal disease who could be expected to do worse. So it's a stage purification issue, I think, and we spend a lot of time on that in the Discussion. 
TABLE E1. Balance in specific comorbidities before and after propensity-score matching. Matching was conducted without considering lymph nodes examined

\begin{tabular}{|c|c|c|c|c|c|c|}
\hline \multirow[b]{2}{*}{ Specific comorbidity } & \multicolumn{3}{|c|}{ Full cohort } & \multicolumn{3}{|c|}{ Matched cohort } \\
\hline & $\begin{array}{l}\text { Lobectomy } \\
(\mathrm{n}=2757)\end{array}$ & $\begin{array}{c}\text { SLR } \\
(n=1229)\end{array}$ & $P$ value & $\begin{array}{l}\text { Lobectomy } \\
(n=1124)\end{array}$ & $\begin{array}{c}\text { SLR } \\
(\mathrm{n}=\mathbf{1 1 2 4})\end{array}$ & $P$ value \\
\hline CAD & $1264(45.8)$ & $606(49.3)$ & .04 & $559(49.7)$ & $554(49.3)$ & .84 \\
\hline Hypertension & $2295(83.2)$ & $1047(85.2)$ & .12 & $943(83.9)$ & 954 (84.9) & .53 \\
\hline $\mathrm{CHF}$ & $393(14.3)$ & $245(19.9)$ & $<.001$ & $216(19.2)$ & $210(18.7)$ & .74 \\
\hline Valve disease & 798 (28.9) & $353(28.7)$ & .89 & $324(28.8)$ & $319(28.4)$ & .82 \\
\hline Diabetes & $859(31.2)$ & $426(34.7)$ & .03 & $376(33.5)$ & $385(34.3)$ & .69 \\
\hline CPD & $1892(68.6)$ & $944(76.8)$ & $<.001$ & $855(76.1)$ & 847 (75.4) & .69 \\
\hline Obesity & $164(5.9)$ & $80(6.5)$ & .5 & $66(5.9)$ & $71(6.3)$ & .66 \\
\hline Anemia & $790(28.7)$ & $409(33.3)$ & .003 & $367(32.7)$ & $357(31.8)$ & .66 \\
\hline PVD & $1043(37.8)$ & $497(40.4)$ & .12 & $459(40.8)$ & 447 (39.8) & .61 \\
\hline CKD & $276(10.0)$ & $156(12.7)$ & .01 & $146(13.0)$ & 134 (11.9) & .44 \\
\hline CVD & $670(24.3)$ & $296(24.1)$ & .88 & $274(24.4)$ & $273(24.3)$ & .96 \\
\hline Weight loss & $254(9.2)$ & $123(10.0)$ & .43 & $110(9.8)$ & $115(10.2)$ & .72 \\
\hline Neurologic disorder & 377 (13.7) & $152(12.4)$ & .26 & $151(13.4)$ & $143(12.7)$ & .61 \\
\hline Hypothyroidism & 714 (25.9) & 304 (24.7) & .44 & $288(25.6)$ & $278(24.7)$ & .63 \\
\hline
\end{tabular}

Values are presented as n (\%). $S L R$, Sublobar resection; $C A D$, coronary artery disease; $C H F$, congestive heart failure; $C P D$, chronic pulmonary disease; $P V D$, peripheral vascular disease, $C K D$, chronic kidney disease; $C V D$, cerebrovascular disease. 